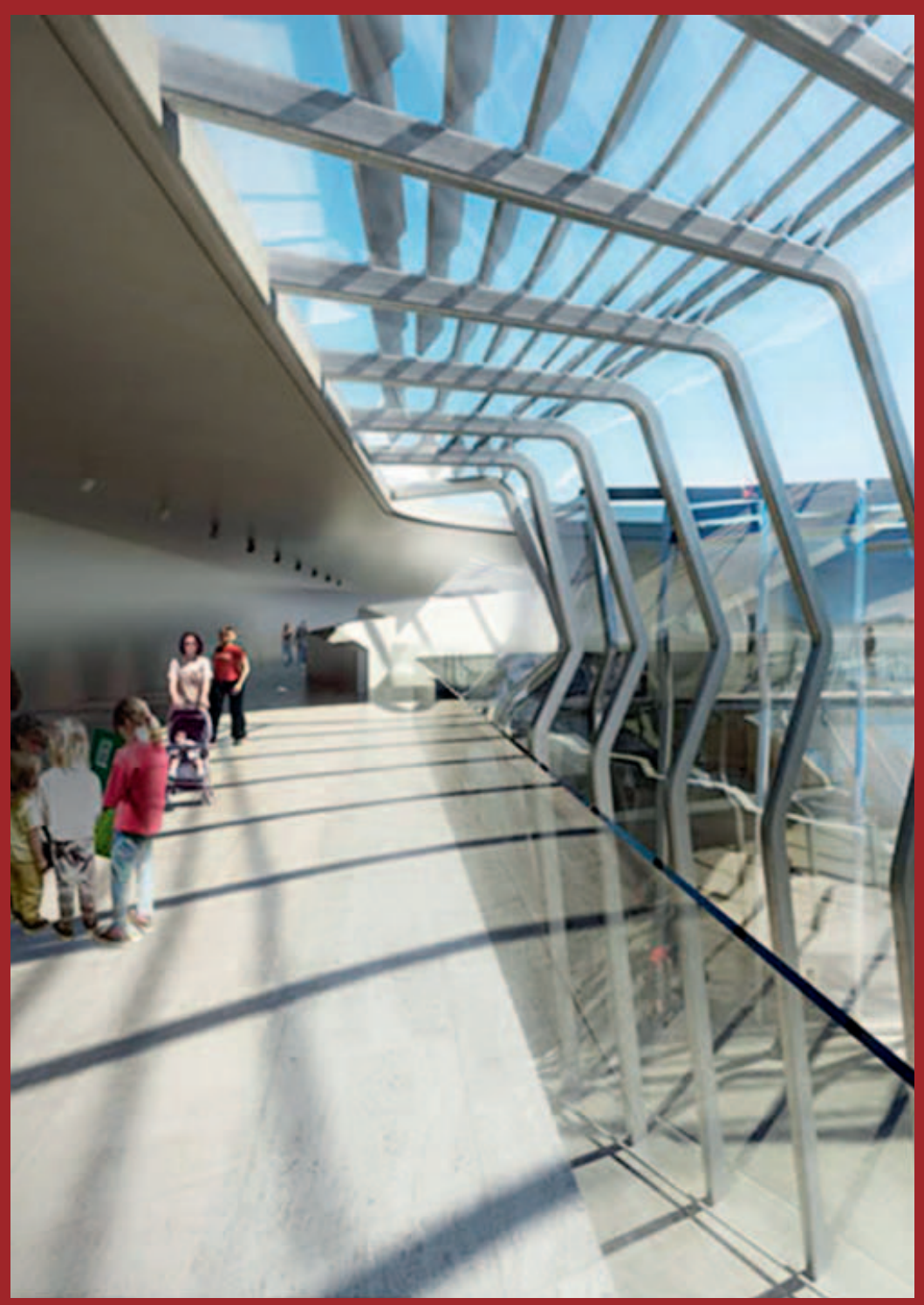

Papalote verde, Monterrey, 2012 


\section{Museografía contemporánea de México. Una primera aproximación en el norte del país}

Rodrigo Witker Barra

Este ensayo tiene como objetivo dar a conocer lo que ha pasado con la infraestructura museográfica de México en los últimos años, particularmente en el norte del país. Ante la imposibilidad de poder hacer un registro y análisis detallado de todo lo que ocurre a nivel nacional, tomamos esta zona como muestra representativa para, a partir de ella, formarnos un panorama del contexto general.

¿Por qué el norte? Porque en esa área geográfica se está produciendo un crecimiento sostenido y rotundo que impacta de manera decisiva en la cartografía museística del país.

Partimos de una pregunta que bajo su simpleza intenta generar polémica: ¿sabemos cuántos museos tenemos en México?. Responderla implica hacer evidente que la información con la que se cuenta es escasa y muchas de las veces incompleta y por lo tanto, poco confiable.

Según el Sistema de Información Cultural (SIC) del Consejo Nacional para la Cultura y las Artes $(\mathrm{CNCA})^{1}$ de México, nuestra infraestructura museística -es decir cuántos museos existen- asciende a 1200 aproximadamente. ${ }^{2}$ Este dato, más allá de su precisión, nos arroja una primera inquietud: si México tiene 112 millones de habitantes, según el censo de 2010, significa que existe un museo por cada 93,000 habitantes. De este modo, la pregunta inicial concatena una serie de reflexiones como ¿son suficientes?, ¿cuántos más son necesarios?, ¿de qué tipo?, ¿cuál es la tipología que estamos generando e impulsando?, ¿tienen calidad?, ¿cuál es la presencia y la distribución que, a nivel geográfico territorial deben tener?

Podríamos pensar que la solución es tan sencilla como el comenzar a registrar y documentarlos, no obstante, ahí precisamente radica otro enorme problema, no hemos adoptado un criterio común de registro, ¿se deben registrar los museos por ubicación, tamaños o temas?

Cuando hablamos de museo, ¿a qué nos referimos?, si hablamos de dimensiones, ¿a un espacio de mil metros?, ¿de cuatro, de ocho mil metros cuadrados?. Independientemente de las necesidades o de las características espaciales, ¿podemos definir un museo "tipo"?, ¿debe tener necesariamente acervo?, ¿debe tener y generar investigación?, en consecuencia ¿debe tener investigadores de planta?, o ¿basta con ser simplemente un espacio de exposición?, ¿debemos registrar su ubicación, su arquitectura, su colección, su dependencia?, ¿el año de creación o de reestructuración?. Esto nos lleva a considerar que cuando hacemos museografía no siempre reflexionamos sobre lo que estamos aportando o cómo estamos impactando y modificando la infraestructura museística del país.

Lo más grave de esto es constatar el hecho de que tenemos escasa y poca información básica actualizada que nos permita diseñar, proponer o recomponer las políticas culturales al respecto.

1 http://sic.conaculta.gob.mx

2 No se sabe con exactitud ya que cada museo decide si es censado o no. 
Un dato a todas luces interesante nos lo da el conocer las temáticas, de áreas de conocimiento y de estudio patrimonial que conforman nuestra infraestructura museística. Hasta el año 2012 encontramos que el 45\% corresponde a museos de antropología; un 16\% a museos de arte; un $9 \%$ a museos de historia; un $10 \%$ a museos de ciencia y tecnología; un $8 \%$ a museos de arqueología y un $12 \%$ a museos de temas diversos. Este diagrama ofrece un panorama de que se trata de un sistema en constante movimiento, pero lo más difícil de todo, es que no sabemos hacia donde debe girar, qué se debe priorizar o reforzar.

Otro aspecto interesante es que el 13\% de los 1200 museos se concentran en el DF, que cuenta ya con 152 museos. Esto implica que la distribución del resto de la oferta museística ubica el 52\% del centro hacia el sur y el 35\% del centro hacia el norte del país.

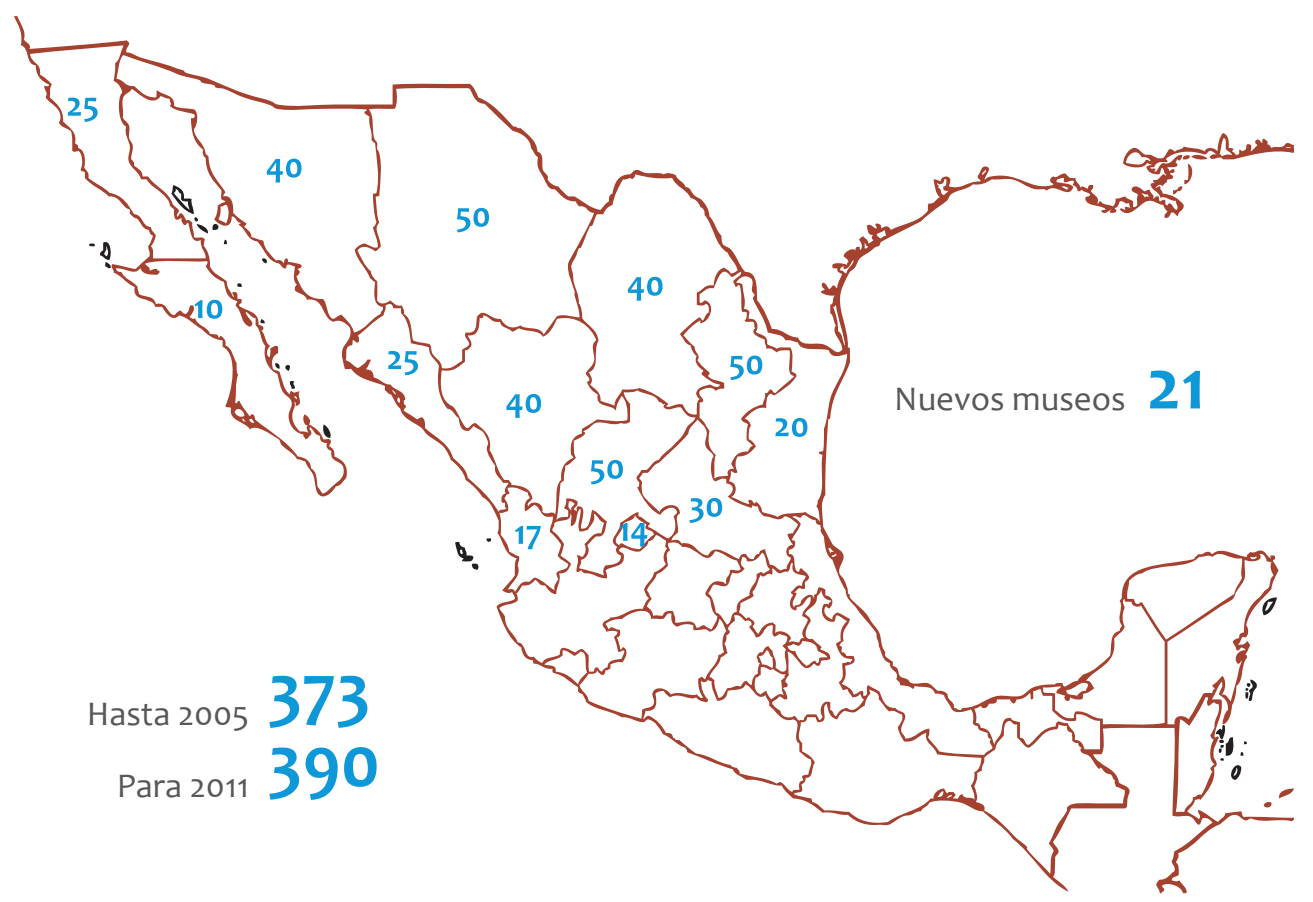

Hasta el año 2005 en el norte del país existían aproximadamente 373 museos, cifra que en el 2011 se incrementó con 21 nuevos museos, es decir 390 museos $^{3}$ (sin considerar remodelaciones ni restructuraciones). Esto revela que los estados del norte con mayor crecimiento en los últimos años son Nuevo León, Chihuahua y Durango con 50 museos; San Luis Potosí y Coahuila con 40 y nos permite, al mismo tiempo constatar otros estados que se han quedado rezagados y que no incrementaron su infraestructura, como Nayarit y Baja California Sur.

De los 21 nuevos museos creados en estos últimos cinco años, ¿cuál es la tendencia? Encontramos que hay 10 nuevos museos de historia, 9 de ciencia y tecnología y 3 de arte $e^{4}$. Esto nos deja ver que, por diversos motivos, principalmente políticos y coyunturales, éstos son los tipos de museos que han predominado en la escena museística del norte del país.

3 Para ello he considerado que el museo "tipo" tiene de $1500 \mathrm{~m} 2$ hacia arriba y genera un impacto rotundo en la oferta museística de la región en la que se aloja.

4 Cabe hacer la mención que en esta muestra encontramos tres casos que refieren a museos de arte, pero su expresión es tan reducida que por lo mismo es hasta alarmante (Musas, Museo de Arte de Sonora, 2009; Museo Arocena, Torreón, 2006 y Cubo, Centro Cultural Tijuana, 2008). 
Lo que significa que en la museología mexicana de los últimos años prevalece dos tipologías: los museos interactivos de ciencia y tecnología y los museos de historia.

Pero, ¿qué tipo de museografía se está haciendo en estos últimos años? Para ello primero debemos intentar definir el término, como una disciplina que no únicamente está acotada por el hecho de resolver técnicamente un espacio dado, sino que también tiene que ver con el contexto donde se ejecuta.

Cuando se hace museografía, es decir se diseñan y planean exposiciones y museos, la mayoría de veces la atención se enfoca en los componentes propios de la narración museográfica y se deja de considerar y estimar las perspectivas y el soporte contextual sobre lo que se trabaja. Si además tomamos en cuenta que museografía, como dice Juan Carlos Rico, es un término caduco que está en constante evolución o según J. Santacana y J.P Lorente, un proceso tan esencial y complejo que mientras más didáctica y crítica sea, mayor impacto tendrán los museos y sus discursos; la tarea, por tanto, será difícil.

¿Cómo entender entonces a la museografía cuándo la mayoría de las veces la concepción que de ella tenemos nos remite al aspecto técnico del proceso de las exposiciones? Propongo que es indispensable provocar la discusión al respecto. El hecho es que la museografía tenga que ver con la construcción del discurso del museo, al mismo tiempo que con la puesta en escena de las exposiciones. Esto nos lleva a considerar que al menos en México, debería definírsele como museología aplicada.

El proceso de la museografía radica entonces en ejecutar una serie de acciones que permitan construir discursos expositivos a través de las exposiciones, que a su vez busca encontrar equilibrio entre las intenciones del mensaje, las estrategias, los recursos y las condiciones que permitan al visitante la autoconstrucción y la apropiación de los mensajes.

\section{El discurso expositivo de las exposiciones}

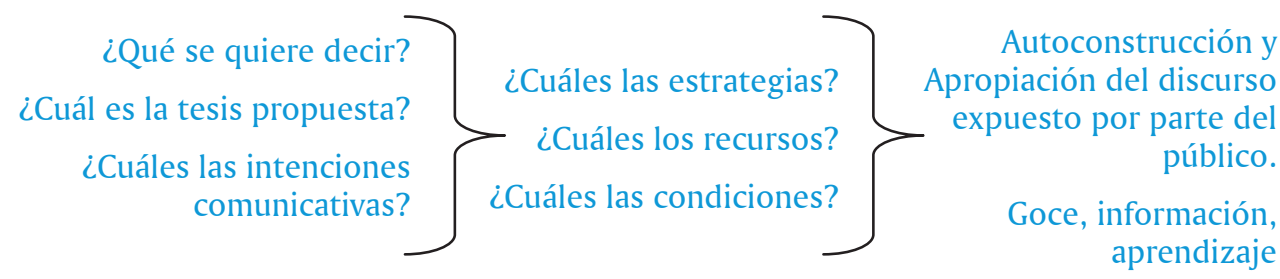

La museografía en este sentido debe dejar de ser un proceso lineal, informativo, direccionado y cerrado para transformarse en un proceso donde la retroalimentación permita medir la eficacia de todo el proceso $^{5}$.

\section{El discurso de las exposiciones de ciencia y tecnología}

Tenemos entonces en la primera línea de trabajo, los museos de ciencia y tecnología. Los creados desde 2005 a la fecha en el norte del país y los que se proponen para 2012, suman 9, cifra que incrementa de manera rotunda y contundente la oferta existente de 127 museos a lo largo del país según la AMMCYT (Asociación Mexicana de Museos de Ciencia y Tecnología). Éstos son Zigzag, Museo Interactivo, Zacatecas, 2005; Museo del Acero, Horno 3, Monterrey, NL, 2007; Laberinto de las Ciencias, San Luis Potosí, 2008; Trompo, Museo Interactivo, 2009; Bebeleche, Museo Interactivo, 2009; Museo El Giroscopio, Saltillo, Coah., 2009; Museo Interactivo Colibrí, San Luis Potosí, 2009; Papalote Verde, Monterrey, NL, 2012

5 En este mismo sentido, como lo hemos dicho anteriormente, las exposiciones museográficas las entendemos como el resultado-tridimensional- obtenido del encuentro entre las formas de interpretación y las formas de representación, cuando el museo expone al público determinados temas o colecciones. 
y La Rodadora, Museo interactivo, Ciudad Juárez, Chih, 2012.

Este tipo de museo es importante por el crecimiento que está experimentando, por la propuesta educativa de sus exposiciones así como por su arquitectura. El museo de ciencia y tecnología no se ocupa únicamente de lo que ocurre dentro del espacio museístico sino que además está proponiendo nuevas formas de entenderse y de proyectarse, precisamente a través de sus formas y volúmenes.

$\mathrm{Su}$ arquitectura se caracteriza por tener grandes dimensiones (desde 2,500m2 en adelante), y con una presencia sólida y muy particular en el

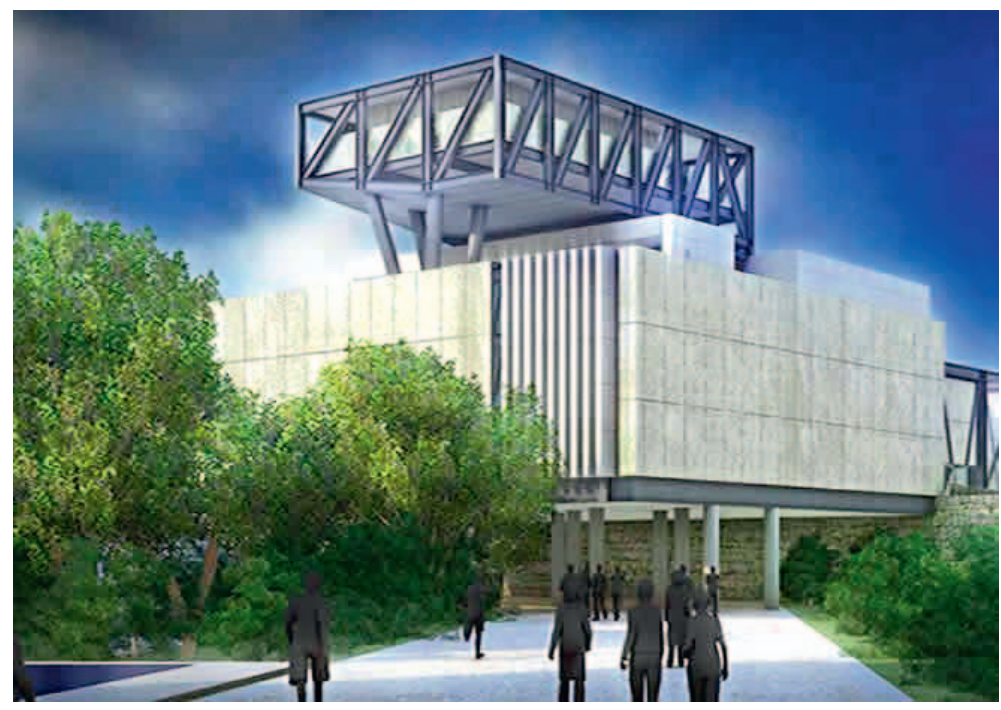

Museo del Mundo Maya, Yucatán, 2012

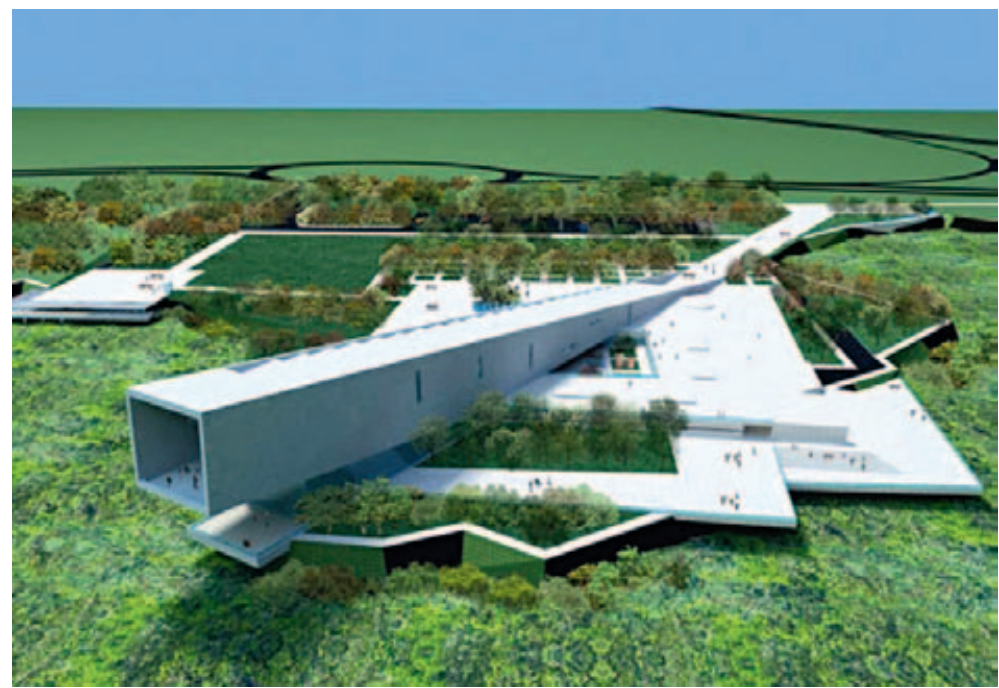

Museo de la civilización Maya, Yucatán, 2012 contexto urbano,

que genera nuevas formas de relacionarse con el medio ambiente. En algunos casos llega incluso a proponer estructuras autosuficientes de manejo de energía de sus instalaciones, como el museo Papalote Verde en Monterrey que se proyecta, por ejemplo, de manera subterránea, desarrollado varios metros bajo la superficie.

El discurso expositivo de lo interactivo se sustenta en el aprendizaje significativo, para lo cual ofrece una serie de estrategias de enseñanza. La museografía entonces, debe permitir la participación, el involucrarse y el descubrir. Para ello los discursos y las instalaciones giran en torno al visitante y no a las colecciones. El conocer -y no suponer, como sucede generalmente en otros tipos de museos- los diversos aspectos que definen al visitante da como resultado la desritualización de la solemnidad de los discursos que repiten las premisas de no mire, no toque. Para este museo el visitante no puede ser pasivo. 


\section{El discurso de las exposiciones históricas}

La segunda tipología observada y que acontece de forma rotunda en el ámbito de los museos en los últimos años es el de la historia, fomentada en gran medida por circunstancias coyunturales sustentadas principalmente en los festejos conmemorativos del Bicentenario de la Independencia (1810) y Centenario de la Revolución Mexicana (1910).

Revisando los proyectos desarrollados nos encontramos con elementos determinantes de cómo el discurso de la historia se está teniendo que adaptar y condicionar a espacios dados, existentes, es decir, circunscritos básicamente a edificios históricos como vemos en Casa Chihuahua, Chihuahua, 2006; Museo de los Metales, Torreón, 2007; Museo del Algodón, Torreón, 2008; Museo del Normalismo, Saltillo, Coahuila, 2008; Museo del Sarape, Saltillo, Coahuila, 2008; Museo Madero, San Pedro, Coahuila, 2008; Museo de la Revolución, 2008, Torreón, Coahuila y Museo del Palacio, Monterrey, 2006. Son muy pocos los casos en los que para la historia se diseñan contenedores ex profeso, podemos encontrar experiencias bastante acertadas pero de ninguna manera podríamos decir que marcan una tendencia, el MUNE, Museo del Noreste, Monterrey, 2008, es un claro ejemplo de ello.

La coyuntura generada por estos festejos conmemorativos significó una espléndida oportunidad de análisis que permiten identificar algunas conclusiones. Enmarcados en el proyecto gubernamental que tenía como objetivos Convertir a México en el museo más grande del mundo; aprovechar el enorme

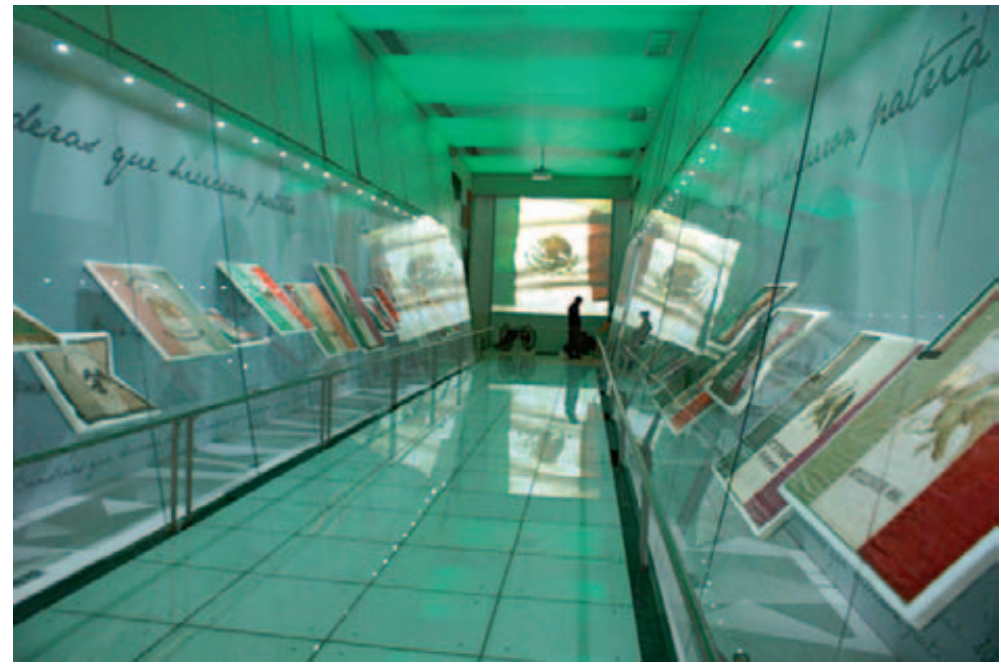

Exposición México 200 años, la patria en construcción patrimonio cultural e histórico que convive con nosotros en las calles de nuestras ciudades y pueblos y ofrecer información sobre 201 sitios arqueológicos y monumentos, se remodelaron más de 30 museos ubicados en rutas geopolíticas que fueron utilizadas por los movimientos independentistas y revolucionarios: el de la Independencia, el de Sentimientos de la Nación, el Trigarante, el de La Revolución, Zapatista y el de la Revolución Constitucionalista.

Como cualquier otro tipo de exposición museográfica, la elaboración de sus discursos expositivos utilizó diversas estrategias y recursos para lograr sus objetivos. Quizá una de las diferencias sustanciales radica en la manera de concebir los discursos expositivos con finales abiertos o cerrados.

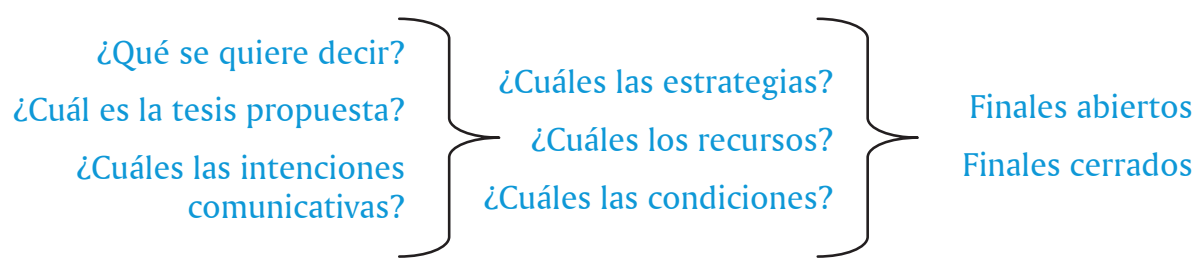


Las estrategias de finales abiertos del discurso expositivo recurren a todo tipo de recursos museográficos: proyecciones, ambientaciones, recreaciones, equipos, dispositivos, equipamientos, iluminación, para involucrar más al visitante en las exposiciones. Son menos rituales y solemnes. Los finales cerrados están condicionados al manejo y operación de objetos originales $y$ en el predominio del criterio cronológico para la comunicación de los acontecimientos históricos y aunque recurren también a todo tipo de estrategias y recursos museográficos, son más contemplativos y

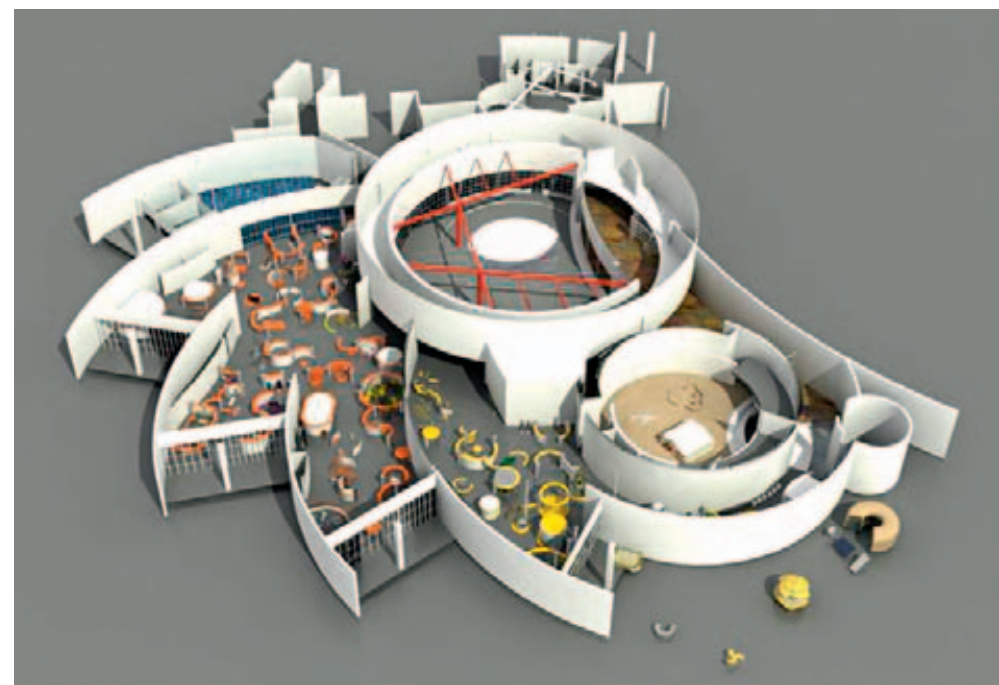

Museo La Rodadora, Ciudad Juárez, 2012

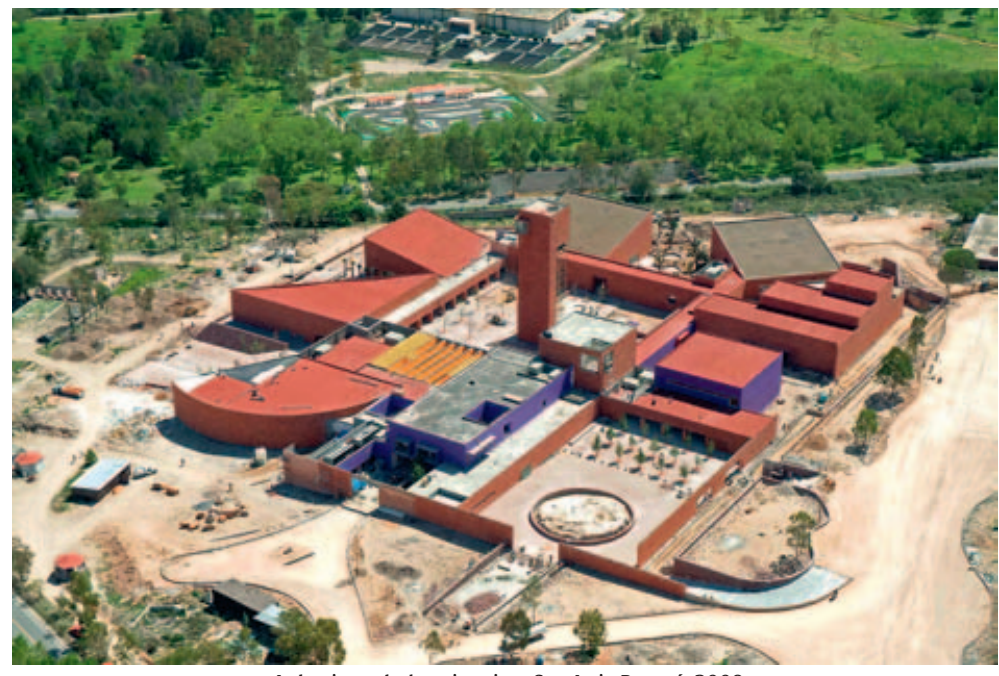

Laberinto de las ciencias, San Luis Potosí, 2008 solemnes.

Uno de los ejemplos más claros de final cerrado fue la exposición temporal México: 200 años, la patria en construcción, instalada en Palacio Nacional, México DF, 2010 y que tuvo una asistencia de más de un millón cien mil visitantes. En este caso el discurso expositivo se sustentó en la originalidad de los objetos patrimoniales y seguía un criterio de orden cronológico, solemne y ritual, impuesto por el peso de la investidura del recinto donde se alojaba. Las estrategias y recursos museográficos que giraban en torno a las colecciones, eran contemplativas y pasivas. Los finales son cerrados porque no ofrecen estrategias de autoconstrucción del mensaje expositivo ${ }^{6}$.

6 Otro ejemplo notable fue la Expo Bicentenario, ubicada en Silao, Guanajuato, 2010, se trató de pabellones de arquitectura efímera construidas en 14.5 hectáreas que fue visitada por más de 3 millones de personas donde se presentaron exposiciones: Pabellón del Mañana, Pabellón de la Memoria, Pabellón del Diálogo, Pabellón de la identidad, que combinaban finales tanto abiertos como cerrados. 
De lo observado podemos concluir:

Esta situación no es exclusiva de México y seguramente se repite en varios países de nuestra América Latina, lo cual no deja de ser preocupante. Conocemos que tenemos aciertos y errores, pero no sabemos cómo medirlos y urge hacerlo para saber si marchamos a buen ritmo o a ciegas ¿Tenemos rumbo y metas?

Es necesario, después de esta revisión, pensar en la creación de un SISTEMA NACIONAL DE MUSEOS, que genere información para implementar políticas culturales en la materia, que resuelva el problema de la documentación patrimonial, que identifique y asesore sobre la infraestructura museística del país; que promocione y regule la normatividad y reglamentación de los procesos museológicos y museográficos; que diagnostique y consolide la formación profesional tanto en la capacitación, actualización

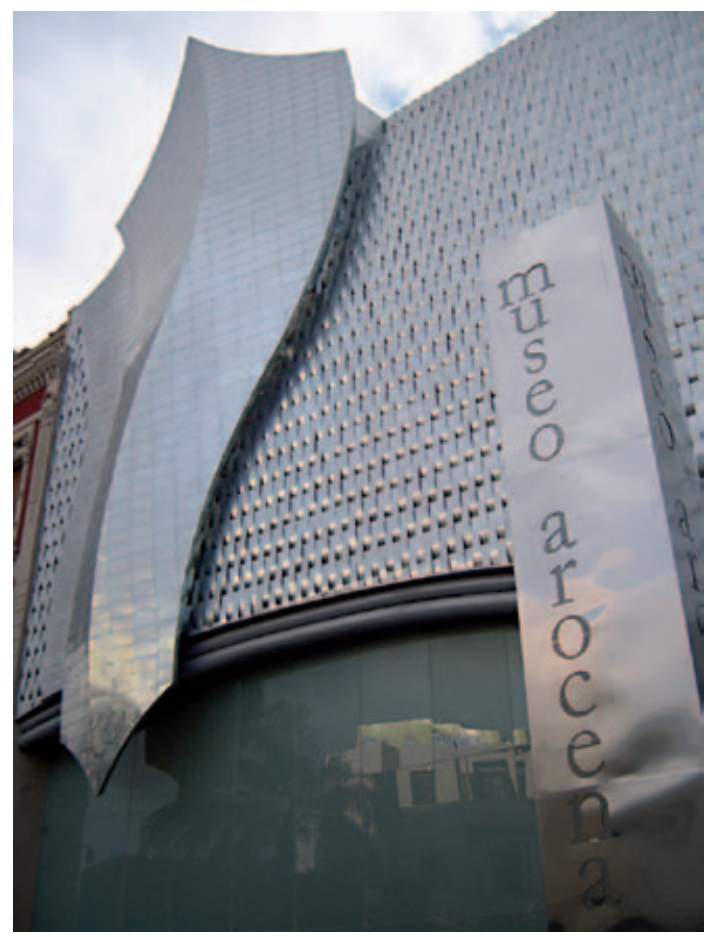

Museo Arocena, Torreón, 2006 o especialización; que promueva la reflexión museológica y museográfica; que promocione publicaciones y que asesore en proyectos de planeación museológica y museográfica. Esta falta de visión acerca del rumbo del panorama museístico nos lleva a avanzar a veces sin rumbo fijo y definido.

Para finalizar queremos reflexionar y llamar la atención sobre un detalle. No conformes con tener el museo del Pueblo Maya en Mérida y otro de la Cultura Maya en Chetumal, para 2012 tendremos un nuevo museo sobre la Civilización Maya y otro sobre el Mundo Maya, todos en Yucatán. Cuatro museos sobre la misma cultura. Sobre esto caben muchas preguntas que resumimos en la siguiente ¿es la cultura Maya la única digna de ser representada? 